\title{
Effects of Spinal Stabilization Exercises Using Visual Feedback on Gross Motor Function and Balance in Children with Cerebral Palsy
}

\author{
So Hee Kim', Tae Ho Kim², Hyun Chul Hwang ${ }^{3}$ \\ 'Department of Physical Therapy, Daegu Dalgubeol General Welfare Center, Daegu; ${ }^{2}$ Department of Physical Therapy, College of Rehabilitation \\ Science, Daegu University, Gyeongsan; ${ }^{3}$ Department of Physical Therapy, Korea Workers Compensation \& Welfare Service Daegu Hospital, Daegu, \\ Korea
}

Purpose: This study examined the effects of spinal stabilization exercises using visual feedback on the gross motor function and balance of the sitting posture in children with cerebral palsy.

Methods: The subjects were 18 children with cerebral palsy aged 8-15 years in the I-III stages of the Gross Motor Function Classification System. The subjects were divided into an experimental group $(n=9)$ and control group $(n=9)$. The experimental group was treated with 30 minutes of neurodevelopmental treatment and 20 minutes of spinal stabilization exercises using visual feedback. The control group was treated with 30 minutes of neurodevelopmental treatment and 20 minutes of spinal stabilization exercises without visual feedback. Both groups participated in the experiment twice a week for eight weeks. The Gross Motor Function Measurement was performed to evaluate the changes between pre- and the post-intervention in gross motor function. The Seated Limit of Stability Surface Area was measured to evaluate the changes in trunk balance.

Results: Both experimental and control groups showed a significant increase in the gross motor function and trunk balance $(p<0.05)$. The experimental group showed a significant increase in gross motor function compared to the control group $(p<0.05)$. The experimental group showed a significant increase in the dynamic trunk balance in all directions when measuring the Seated Limit of Stability Surface Area $(p<0.05)$.

Conclusion: Spinal stabilization exercises using visual feedback for the neurodevelopmental treatment of children with cerebral palsy can improve their gross motor function and trunk balance when in a sitting posture more effectively.

Keywords: Cerebral Palsy, Stabilization, Visual feedback

\section{서 론}

뇌성마비는 발달 중인 태아 혹은 출생 후 2 년 이내 발생한 영아기의 미성숙한 뇌에 비진행적 손상에 의해 운동 및 자세 발달에 영구적인 손상으로 활동의 제한을 갖는 질환이다.' 정상 발달 과정 중 생후 6 개 월경에 바로 누운 자세에서 턱을 당기고 머리를 드는 것은 머리를 조 절하는 항중력 굴곡근(antigravity flexor muscle)이 발달하는 것이다. ${ }^{2}$ 아이가 성장하면서 습득하는 최초의 반응은 정위 반응(righting reaction)이며 약 10-12개월까지 가장 효과적으로 아이에게 영향을 미치 고, 공간에서 머리를 정상적인 자세로 보호해 주면서 머리·목·몸통, 몸통과 사지를 정상적인 정렬로 맞추게 해 준다. 아이가 성장할 때 시
각은 빠르게 작용하여, 머리와 몸통을 정상적인 자세로 유지시켜주 는 중요한 요인이 된다.,4 뇌성마비 아동은 머리의 조절과 몸통의 안 정성이 떨어져서 올바른 자세를 유지하거나 균형을 잡기가 어렵기 때 문에, ${ }^{5}$ 뇌성마비 아동의 머리 조절과 몸통의 안정성은 치료를 통해 개선하여 정상적인 움직임의 기회를 가지게 해야 한다. ${ }^{6}$

감각기관들 중 시각과 안뜰기관은 머리를 조절하여 조화로운 방향 감과 균형을 주고, ${ }^{2}$ 시각은 주위상황과 거리의 변화에 대해 거의 동시 에 정보를 제공하는 능력이 뛰어나다. ${ }^{8}$ 신체 및 환경에서 오는 정보는 목과 몸통에 동일하게 전달되어 머리와 목 근육을 포함한 사지 움직 임의 협응을 가능하게 하고 그중 머리와 목의 기능은 주변 환경에 대 한 신체의 기준을 설정하고 자세를 조절하는 동안 머리와 시각, 안뜰 
기관을 위한 안정된 기저면(base of support, BOS)을 가능하게 만든다.9 올바른 몸통의 정렬을 인식하기 위해서는 정상적인 운동감각이 필요하며 이것은 피부, 근육, 관절에 분포되어 있는 체감각수용기의 입력에 의해 크게 영향을 받는다. ${ }^{10}$ 감각계의 기능이 떨어지는 뇌성마 비 아동은 감각되먹임(sensory feedback)과 같은 적절한 감각자극 입 력을 통한 훈련으로 치료를 할 수 있다. ${ }^{11}$ 시각 및 청각되먹임을 이용 하여 뇌성마비 아동을 훈련한 결과 좌우 대칭적 서기 자세가 효과적 이었고, ${ }^{12}$ 시각되먹임을 이용한 목 운동은 경직성 양하지마비 아동의 선 자세에서 대칭적 균형 조절 능력과 대동작 기능을 향상시켰다는 연구를 보면, ${ }^{4}$ 감각되먹임 중 시각되먹임을 이용한 운동이 뇌성마비 아동의 치료에 효과가 있다는 것을 알 수 있다. 만성 뇌졸중 환자를 대상으로 한 연구에서도 시각적 되먹임 훈련과 몸통 안정화 운동, 이 두 가지 훈련을 접목한 복합 운동을 적용하였을 때 체간 안정화 운동 은 정적 균형 능력에, 시각적 되먹임 훈련은 동적 균형 능력에 효과가 있었다고 하였다. ${ }^{13}$

뇌성마비 아동에게 머리와 몸통을 안정되게 하는 척추 안정화 운 동을 적용한 이전 연구에서는, 양측형 경직성 뇌성마비 아동 중 $\mathrm{GM}-$ FCS level III-IV의 학령기(6-12세) 아동을 대상으로 몸통근력강화 운 동 프로그램을 수행한 집단에서 직접적으로는 몸통의 기능적 근력 몸통 조절 능력, 앉기 자세 제어 능력, 대근육 운동기능에, 간접적으 로는 사물 조작 능력 및 가동성, 일상생활동작 수행력에 보다 유의한 향상을 가져왔다고 하였다. ${ }^{14}$ 조산으로 인한 경직성 양하지 마비 아 동에게도 목 근육 강화 운동을 통한 몸통의 근육 활동 향상을 통해 조산으로 인한 경직성 양하지 마비 아동에서 흔히 나타나는 머리의 불안정성과 몸통과의 연결성 부족에 대한 문제점을 해결할 수 있는 보다 효율적인 치료 중재를 제안하였다. ${ }^{15}$ 뇌졸중 환자를 대상으로 한 연구에서도 중추신경계 발달 치료를 이용한 몸통 하부 안정화 운 동을 뇌졸중 환자에게 5주간 적용한 연구에서 균형능력과 보행능력 에서 운동 전후의 긍정적인 변화를 보였다고 하였다.16
머리와 몸통의 안정성에 효과적인 척추 안정화 운동과 시각되먹임 을 이용한 운동은 뇌성마비, 뇌졸중 등 다양한 대상자들에게 이미 연구되어 왔다. 그러나 뇌성마비 아동을 대상으로 척추 안정화 운동 에 시각되먹임을 이용한 실험에 관한 연구는 미미한 실정이다. 그러 므로 본 연구는 선행 연구된 척추 안정화 운동에 시각되먹임을 이용 하여 뇌성마비 아동에게 더 효과적인 운동 프로그램을 제시하고자 한다.

\section{연구 방법}

\section{1. 연구대상}

본 연구는 대학병원과 재활전문병원에서 뇌성마비로 진단을 받고 대 구 소재 소아전문물리치료실이 있는 기관에서 물리치료를 받고 있 고, 뇌성마비 분류체계인 대동작기능분류체계(gross motor function classification system, GMFCS)의 1-5단계 중 1-3단계로 분류되고, 8세 이상에서 15 세 이하의 학령기 뇌성마비 아동 18 명을 연구대상자로 선정하였다. 아동들과 부모님들에게 본 연구의 취지를 충분히 설명 하고 실험 참여 동의를 받은 후 아동들을 무작위로 실험군 9명과 대 조군 9명으로 나누었다. 본 연구는 IRB 승인(IRB 승인번호 1040621201702-HR-014-02)을 받은 후 진행하였다. 실험군과 대조군의 일반적 인 특성에 대한 집단 간의 동질성 검정을 실시한 결과 통계학적으로 유의한 차이가 없었다 $(\mathrm{p}>0.05)($ Table 1$)$.

\section{2. 실험방법}

\section{1) 측정도구}

(1) 대동작기능 평가

뇌성마비 아동의 대동작기능의 평가를 위해 대동작기능평가(gross motor function measurement, GMFM)를 이용하였다. 뇌성마비 아동 의 시간의 경과에 따른 대동작기능의 변화를 측정해 주는 표준화된

Table 1. General characteristics of subjects

\begin{tabular}{|c|c|c|c|c|}
\hline & & $E G(n=9)$ & $C G(n=9)$ & $\mathrm{p}$ \\
\hline \multirow[t]{2}{*}{ Gender } & Male & 3 & 3 & \\
\hline & Female & 6 & 6 & \\
\hline Age (yr) & & $12.9 \pm 2.8$ & $12.2 \pm 2.2$ & 0.58 \\
\hline Height (cm) & & $147.1 \pm 14.3$ & $140.4 \pm 13.1$ & 0.32 \\
\hline Weight (kg) & & $45.0 \pm 12.1$ & $36.1 \pm 12.3$ & 0.14 \\
\hline \multirow[t]{3}{*}{ Level of GMFCS } & Level I & 4 & 3 & \\
\hline & Level II & 1 & 2 & \\
\hline & Level III & 4 & 4 & \\
\hline \multirow[t]{2}{*}{ Type of cerebral palsy } & Spastic diplegia & 5 & 5 & \\
\hline & Spastic quadriplegia & 4 & 4 & \\
\hline
\end{tabular}

Mean \pm standard deviation.

GMFCS: gross motor function classification system, EG: experimental group, CG: control group. 
평가도구로 평가는 다섯 가지 영역으로 나누어져 있다. 눕기와 뒤집 기 17항목, 앉기 20항목, 네발기기와 무릎서기 14항목, 서기 13항목, 걷 기와 달리기 그리고 도약하기 24 항목의 총 88 개의 항목을 평가한다. 측정자 내 신뢰도는 0.92-0.99, 측정자 간 신뢰도는 $0.87-0.99$ 로 높은 신 뢰도를 가진다.17

\section{(2) 균형능력 측정}

대상자의 앉은 자세에서의 균형능력을 평가하기 위한 몸통 안정성 측정 도구로 균형능력측정 및 훈련시스템인 바이오레스큐(Biorescue, RM Ingenierie, France)를 사용하였다. 발이 닿지 않는 앉은 자세에서 엉덩관절 $90^{\circ}$, 무릎관절 $90^{\circ}$ 를 유지하며 손은 교차하여 가슴 위에 위 치하고 시선은 전방 모니터를 향하게 한 후 화면에 보이는 화살표에 따라 신체를 기울여 목표지점까지 체중을 옮기는 앉은 자세에서의 안정성 한계(seated limit of stability)를 측정하였다. 안정성 한계의 총 면적과 좌우의 면적 비율, 전후의 면적 비율을 측정하여 동적 안정성 을 측정하였다. ${ }^{18}$

\section{2) 중재방법}

중재 전, 뇌성마비 아동의 대동작기능을 평가하기 위해 대동작기능 평가(GMFM), 몸통의 균형능력 측정을 위해 바이오레스큐(Biorescue, RM Ingenierie, France)를 이용하여 평가를 실시하였다. 실험군은
기존의 신경발달학적 물리치료 30 분에 시각되먹임을 이용한 척추안 정화 운동 20 분을 추가하여 총 50 분 운동을 실시하는 치료적 중재를 실시하였다. 대조군은 기존의 신경발달학적 물리치료 30 분에 시각되 먹임을 이용하지 않는 척추 안정화 운동 20 분을 추가하여 총 50 분 운 동을 실시하였다. 주 2 회씩 8 주간 운동하였고 두 그룹 모두 8 주간 운 동을 모두 마친 후 중재 후 똑같은 평가를 실시하였다. 실험군과 대조 군 모두 신경계 물리치료에 대해 전문적인 지식을 습득하고 치료경 력 5 년 이상인 물리치료사가 아동을 치료하였고, 각 동작마다 1 회 실 시할 때 10 초 유지하고 10 회 반복하였다.18

\section{(1) 시각되먹임을 이용한 척추 안정화 운동}

선행연구에서 뇌성마비 아동에게 효과적인 척추 안정화 운동 4 가지 를 선택하여, $14,18,19$ 아동에게 레이저 포인터를 부착한 모자를 씨우게 하여, ${ }^{4}$ 운동 시 레이저 포인터로 과녁을 맞추게 해서 시각을 이용하여 관련 근육들의 수축을 유도하였다.

\section{(1) 시각되먹임을 이용한 깊은목굽힘근 운동(cranio-cervical flexion} exercise using visual feedback)

바로 누운 자세에서 머리를 가운데로 유지하고 시선을 아래쪽으로 향하게 하여 턱을 안으로 끌어당기면서 아동의 정면이나 천장에 설치 한 과녁을 아래로 맞추게 하여 후두하부를 누르게 하여 경부와 상부
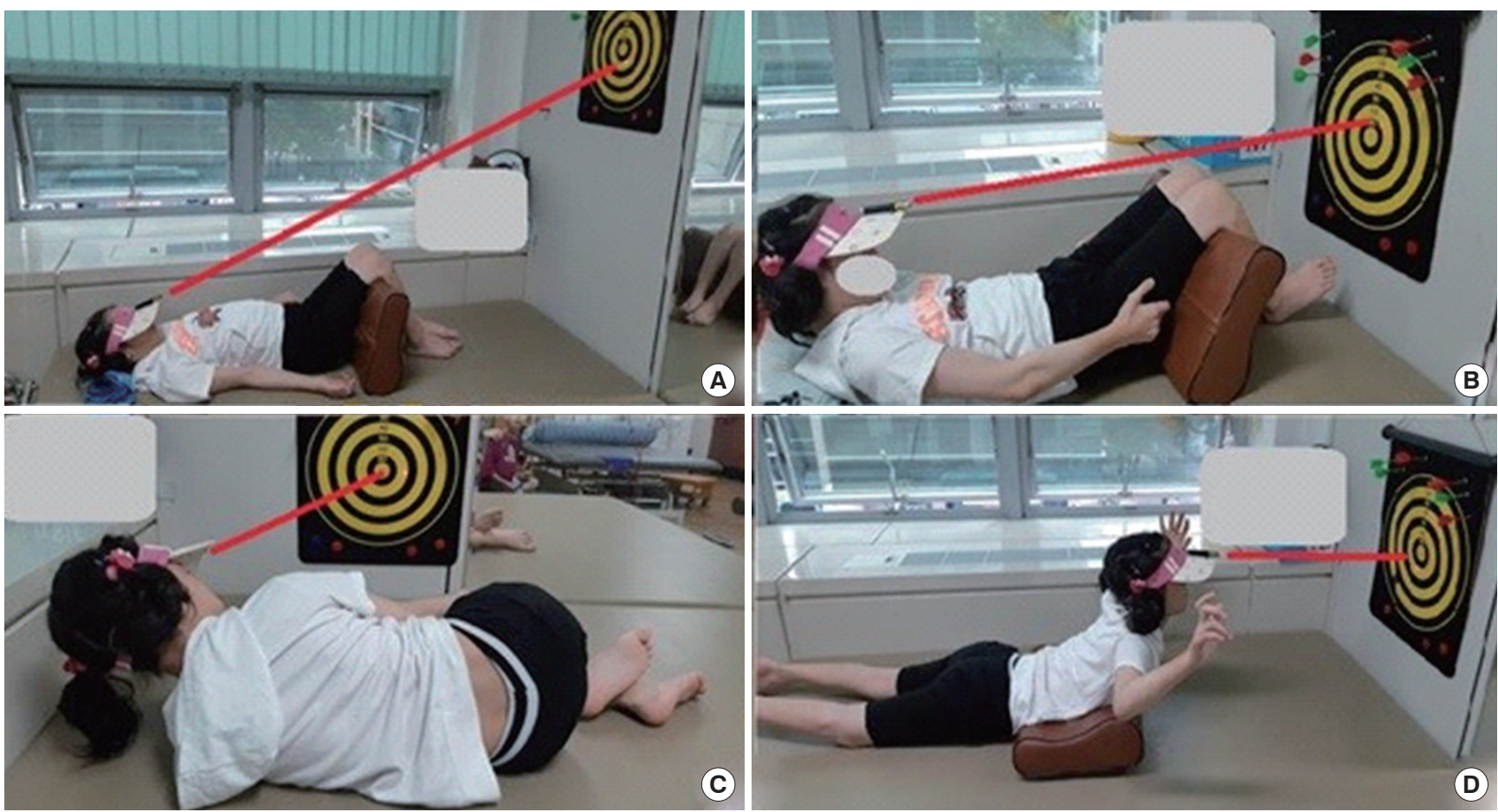

Figure 1. Spinal stabilization exercises using visual feedback. (A) Cranio-cervical flexion exercise using visual feedback. (B) Curl up exercise using visual feedback. (C) Neck side-flexion in side-lying position using visual feedback. (D) Superman prone exercise using visual feedback. 
흥추의 심부근인 긴 목근과 긴머리근을 활성화시키는 깊은목굽힘근 운동을 실시한다. 목뼈의 정상적 전만을 편안히 유지하고 얕은 목굽 힘근인 목빗근과 앞목갈비근의 이완을 유지하게 한다(Figure 1A).

(2) 시각되먹임을 이용한 윗몸일으키기운동(curl up exercise using visual feedback)

바로 누운 자세에서 무릎을 구부리고 머리와 몸을 가운데 유지하도 록 정렬을 맞추고 턱을 안으로 당기면서 목 굽힘과 동시에 머리 들기 를 실시하여 전방의 과녁을 바라보면서 레이저를 위에서 아래로, 좌 우로, 대각선 방향으로 위에서 아래로 맞추게 하여 경부의 굴곡근과 체간의 하복부 근육을 함께 활성화시킨다(Figure 1B).

\section{(3) 시각되먹임을 이용한 옆으로 누운 자세에서의 목 측방 굴곡하기(neck}

side-flexion in side-lying position using visual feedback)

옆으로 누운 자세에서 고개를 수직으로 들어서 레이저를 과녁에 좌 우로, 대각선 방향으로 위에서 아래로 맞추게 한다. 반대편 옆으로 누 워서도 똑같이 실시한다. 이때, 아동의 어깨가 올라가는 보상 작용이 일어나지 않도록 한다(Figure 1C)

(4) 시각되먹임을 이용한 엎드린 자세에서의 슈퍼맨 운동(superman prone exercise using visual feedback)

엎드린 자세에서 머리를 들고 과녁을 아래에서 위로, 좌우로, 대각선 방향으로 아래에서 위로 맞추게 한다. 과녁을 위와 같은 방향으로 맞 추면서 머리 들고 유지하기, 머리 들면서 양팔을 들고 유지하기, 머리 들고 가슴까지 들어올리기, 머리와 양팔 들기를 동시에 수행, 머리와 두 다리 들기를 동시에 수행하는 운동을 아동의 상태에 따라 단계별 로 실시한다(Figure 1D).

\section{(2) 신경발달학적 물리치료}

아동의 개별적인 기능적 수준을 고려하여 근 긴장도 조절, 신체 근위 부 활성화, 정상에 가까운 자동적인 움직임 유도 등 기존의 신경발달 학적 접근법을 이용한 물리치료를 실험군, 대조군 모두 30 분 동안 실 시하였다.

\section{3. 분석방법}

실험군과 대조군 내의 실험 전후 대동작기능과 균형능력의 변화 비 교는 정규성 검정을 만족하지 못하여 비모수 검정인 윌콕슨 부호 순 위 검정(Wilcoxon signed rank test)을 사용하였고, 대조군과 실험군 간 의 실험 전후 비교 데이터 또한 정규성 검정을 만족하지 못하여 비모 수 검정인 맨휘트니-U 검정(Mann-Whitney-U test)을 통하여 분석하 였다. 자료 처리의 분석은 SPSS 22.0 for Window를 사용하였고 유의 수준은 $\mathrm{p}=0.05$ 로 하였다.

\section{결 과}

\section{1. 대동작기능 평가}

중재 전후 실험군과 대조군의 대동작기능평가(GMFM) 결과가 모두 유의하게 증가하였고 $(\mathrm{p}<0.05)$, 두 집단 간의 중재 전후 차이 값에서 유의한 차이가 있었다 $(\mathrm{p}<0.05)$ (Table 2).

\section{2. 균형능력 측정}

중재 전후 앉은 자세의 안정성 한계의 이동 면적(seated limit of stability surface area) 측정 결과는 실험군에서 좌우, 전후로 체중을 이동하여 움직이는 모든 방향에서 유의하게 증가하였다 $(\mathrm{p}<0.05)$. 대조군에서 는 전측을 제외한 총 이동 면적, 좌, 우, 후측에서 유의하게 증가하였 다 $(\mathrm{p}<0.05)$. 두 집단 간의 중재 전후 차이 값에서는 총 이동 면적, 좌 우, 전후측 모두에서 유의한 차이가 없었다( $\mathrm{p}>0.05)$ (Table 3).

\section{고 찰}

대동작기능 중 몸통의 근육은 서 있거나 앉아 있는 동안에 신체의 정 렬을 유지하고 척추의 안정성을 유지하고 신체의 기능을 수행하는 데 필수적인 요소이고 사지를 움직이거나 균형을 유지하기 위한 기 본적인 지지대이다. ${ }^{20}$ 정상 발달과정을 가지지 못한 뇌성마비 아동은 몸통 근육의 약화로 몸통의 안정성을 상실하게 된다.21 따라서 뇌성 마비 아동의 기능적인 움직임의 향상을 위해서 먼저 관심을 가져야 할 부분은 몸통의 안정성이다. ${ }^{20}$ 몸통 근력 강화 운동이 대근육 운동

Table 2. Comparison of GMFM

(unit: \%)

\begin{tabular}{|c|c|c|c|c|c|c|}
\hline & & Pre & Post & Difference pre-post & z & $\mathrm{p}$ \\
\hline \multirow[t]{4}{*}{ GMFM } & EG & $70.93 \pm 25.02$ & $77.30 \pm 23.55$ & $6.37 \pm 2.87$ & -2.67 & $0.01^{*}$ \\
\hline & CG & $67.68 \pm 20.01$ & $69.96 \pm 21.53$ & $2.28 \pm 2.08$ & -2.52 & $0.01^{*}$ \\
\hline & z & -0.22 & & -2.52 & & \\
\hline & $\mathrm{p}$ & 0.86 & & $0.01^{*}$ & & \\
\hline
\end{tabular}

GMFM: gross motor function measurement, EG: experimental group, CG: control group, Pre: pre intervention, Post: post intervention, Difference pre-post: difference pre-post intervention.

${ }^{*} p<0.05$. 
Table 3. Comparison of seated limit of stability surface area

(unit: $\mathrm{mm}^{2}$ )

\begin{tabular}{|c|c|c|c|c|c|c|}
\hline & & Pre & Post & Difference pre-post & $z$ & $\mathrm{p}$ \\
\hline \multirow[t]{4}{*}{ Seated LOS total surface area } & EG & $3,932.11 \pm 3,398.09$ & $8,200.11 \pm 5,614.23$ & $4,268.00 \pm 3,484.28$ & -2.67 & $0.01^{*}$ \\
\hline & CG & $3,832.56 \pm 3,075.20$ & $5,586.11 \pm 3,912.27$ & $1,753.56 \pm 1,724.55$ & -2.67 & $0.01^{*}$ \\
\hline & z & -0.04 & & -1.72 & & \\
\hline & $\mathrm{p}$ & 1.00 & & 0.09 & & \\
\hline \multirow[t]{4}{*}{ Seated LOS left surface area } & EG & $1,863.22 \pm 1,547.46$ & $4,044.00 \pm 2,860.30$ & $2,180.78 \pm 1,722.01$ & -2.55 & $0.01^{*}$ \\
\hline & CG & $1,804.33 \pm 1,480.80$ & $2,885.44 \pm 2,209.70$ & $1,081.11 \pm 1,081.54$ & -2.67 & $0.01^{*}$ \\
\hline & $z$ & -0.04 & & -1.72 & & \\
\hline & $\mathrm{p}$ & 1.00 & & 0.09 & & \\
\hline \multirow[t]{4}{*}{ Seated LOS right surface area } & EG & $2,068.89 \pm 1,885.04$ & $4,156.22 \pm 2,916.70$ & $2,087.33 \pm 2,058.02$ & -2.31 & $0.02^{*}$ \\
\hline & CG & $2,028.89 \pm 1,647.86$ & $2,700.78 \pm 1,728.71$ & $671.89 \pm 820.09$ & -2.07 & $0.04^{*}$ \\
\hline & z & -0.31 & & -1.10 & & \\
\hline & $\mathrm{p}$ & 0.80 & & 0.30 & & \\
\hline \multirow[t]{4}{*}{ Seated LOS anterior surface area } & EG & $2,474.44 \pm 2,325.41$ & $4,796.11 \pm 3,773.51$ & $2,321.67 \pm 2,449.05$ & -2.07 & $0.04^{*}$ \\
\hline & CG & $2,134.78 \pm 1,789.24$ & $2,734.22 \pm 2,111.63$ & $599.44 \pm 728.65$ & -1.84 & 0.07 \\
\hline & z & -0.13 & & -1.01 & & \\
\hline & $\mathrm{p}$ & 0.93 & & 0.34 & & \\
\hline \multirow[t]{4}{*}{ Seated LOS posterior surface area } & EG & $1,457.56 \pm 1,403.50$ & $3,404.11 \pm 1,985.88$ & $2,593.22 \pm 1,819.27$ & -2.67 & $0.01^{*}$ \\
\hline & CG & $1,697.89 \pm 1,298.82$ & $2,852.00 \pm 2,005.29$ & $1,154.11 \pm 1,358.68$ & -2.31 & $0.02^{*}$ \\
\hline & z & -0.66 & & -1.81 & & \\
\hline & $\mathrm{p}$ & 0.55 & & 0.08 & & \\
\hline
\end{tabular}

EG: experimental group, CG: control group, Pre: pre intervention, Post: post intervention, Difference pre-post: difference pre-post intervention, LOS: Limit of Stability. ${ }^{*} \mathrm{p}<0.05$.

기능에 긍정적인 영향을 주었고, ${ }^{21}$ 목과 몸통의 안정화 운동이 부족 했던 조산으로 인한 뇌성마비 아동에게 목과 몸통근의 활성화를 유 도하면 안정성이 향상되면서 움직임의 범위 증가와 함께 대동작기능 의 증진에 영향을 주었다는 연구가 있다. ${ }^{18}$ 본 연구에서의 대동작기능 변화 결과는 실험군과 대조군 모두 중재 전후에서 유의하게 증가하 였는데, 선행연구의 결과와 같이 척추의 안정성을 높이는 실험군과 대조군의 운동이 몸통의 근육을 발달시켜서 뇌성마비 아동의 대동 작기능을 향상시켰다고 볼 수 있다. 특히 시각되먹임을 이용한 실험 군에서 대동작기능이 더 유의하게 증가하였는데, 시각되먹임을 이용 한 훈련은 시각정보를 이용하여 환자에게 흥미를 유발시켜 치료에 더욱 집중할 수 있게 하고 스스로 운동을 유도하여 치료의 효과를 더욱 높일 수 있었다는 연구의 결과처럼, ${ }^{22}$ 실험군에서 시각되먹임을 이용하여 동기유발을 촉진한 것이 보다 더 효과적으로 대동작기능 을 향상시켰을 것이라고 본다.

시야 및 시각적 정확성은 균형 및 이동 능력에 영향을 미치는 중요 한 인자이고, 시각적 정확성에 문제를 가진 사람은 자세의 균형 능력 에 어려움을 가지게 된다. ${ }^{23}$ 시각기능장애는 뇌성마비 아동의 자세 조절에 뚜렷한 역할을 수행한다. ${ }^{4}$ 뇌성마비 아동의 자세 조절과 시지 각 결핍의 문제는 서로 다른 개별적인 문제로 접근되고 있지만 발달 과정에 있는 아동들이 성장함에 따라 서로 상충되어 더 큰 기능적 활동들의 문제점이 되므로 시지각과 자세 조절을 위한 동시적인 접
근이 필요하다. ${ }^{24}$ 안구와 자세 조절은 뇌줄기에 있는 안구의 조절에 관련된 핵들과 안뜰신경핵 간의 신경회로망을 형성하여 동시적으로 조절된다. 안뜰신경핵은 눈을 포함하는 머리의 움직임을 조절하는 역할도 하며 머리의 움직임에 상관없이 안구가 고정될 수 있도록 한 다. ${ }^{25}$ 안뜰안구반사(vestibulo-ocular reflex, VOR)에서 안뜰신경은 안 뜰기관의 기능에 따라 안구의 움직임뿐 아니라 사지와 몸통, 목의 운 동 조절에도 깊은 관여를 하고 있다. ${ }^{24}$

시각에 관한 다양한 연구들을 종합해 볼 때, 뇌성마비 아동을 치 료할 때 안구의 운동 기능이 신체의 기능을 회복시키는 데 중요하 고, ${ }^{26}$ 안구 운동 프로그램이 경직형 뇌성마비 아동의 자세 조절 및 시 지각 능력에 효과가 있다고 볼 수 있다. ${ }^{24}$ 따라서 뇌성마비 아동의 눈 이 자동적으로 머리의 움직임을 따라 움직이면서 중심축으로 유지 하는 것이 비대칭적으로 증가된 근 긴장도를 낮추고 머리 조절이 어 려운 아동의 치료에 기본적인 접근이라고 할 수 있다. ${ }^{27}$ 본 연구의 실 험군에서 레이저 포인터로 과녁을 향하여 눈을 따라 움직이는 운동 을 했을 때, 안구 운동에 관한 선행연구처럼 뇌성마비 아동에게 직접 적인 안구 운동을 적용하지는 않았으나, 아동은 자연스럽게 안구 운 동을 하게 되었다. 그 결과 척추의 움직임에 따라서 안뜰안구반사 (VOR)가 작용을 하여 척추의 자동적인 자세 조절과 눈 움직임이 협 응이 되면서 신체의 안정성이 확보가 되었고, 그로 인하여 대동작기 능을 수행하는 데 필수적인 요소인 척추 근육들의 선행 조절로 인하 
여 대동작기능이 향상되었다고 볼 수 있다.

본 연구에서 앉은 자세에서 안정성 한계의 이동 면적을 이용한 균 형 능력 평가 결과는 중재 후 실험군에서 좌우, 전후로 체중을 이동 하여 움직이는 동적 몸통 균형 능력에서 유의하게 증가하였다. 대조 군에서는 전측을 제외한 좌, 우, 후 이동면적에서 유의하게 증가하였 다. 이것은 신체의 안정성이 증가하고 몸통의 조절 능력이 좋아지면 넓고 다양한 범위로의 움직임이 가능해지고 동시에 움직일 수 있는 면적이 증가하기 때문에, ${ }^{18}$ 앉은 자세에서 안정성 한계의 이동 면적 범 위의 증가로 실험군, 대조군 모두에서 동적 몸통 균형 능력이 증가된 것이다. 두 집단 간의 중재 전과 후의 차이에서는 체중을 이동하여 움 직이는 동적 균형 능력이 유의한 차이가 없었다. 그러나 실험군에서 모든 방향으로 체중 이동 움직임이 유의하게 증가하였으므로 시각되 먹임을 이용한 척추 안정화 운동이 동적 균형 능력에 영향을 미친다 는 연구의 의미가 있다. 본 연구에서 안구의 운동이 대동작기능에 영 향을 미친 것처럼, 과녁을 향하여 눈을 움직일 때 머리와 척추의 움직 임에 따른 안뜰안구반사의 작용과 스스로 몸을 움직일 때 균형을 잡 는 동적 균형 능력이 협력하여 상승 작용으로 동적 균형 능력이 향상 되었다고 볼 수 있다. 이것은 안구운동 조절 능력과 균형감각 사이에 는 밀접한 관계가 있다는 연구로 알 수 있다. ${ }^{28}$

균형 조절 장애를 가진 환자의 자세조절에 시각적 생체 되먹임 운 동을 체중부하 운동방법으로 제시한 연구, ${ }^{29}$ 율동적인 자세 변화를 통한 시각되먹임 훈련이 뇌졸중 환자의 동적 균형 능력을 향상시켰 다는 연구, ${ }^{30}$ 경직성 편마비 아동들에게 가상현실 프로그램으로 시 각적 자극을 이용하여 아동의 머리 위치를 재정비함으로써 선 자세 에서의 균형을 향상시킨다는 연구 ${ }^{27}$ 등은 운동 학습에 중요한 요소 인 시각되먹임을 이용한 치료에 관한 것이다. 본 연구에서도 시각되 먹임을 적용한 선행연구에서와 같이 뇌성마비 아동에게 시각되먹임 을 이용하여 척추 안정화 운동을 하게 하였다. 처음에는 척추의 조절 을 능숙하게 하지 못하여 과녁을 잘 맞추지 못하였으나 레이저 포인 터로 과녁을 맞추는 시각되먹임을 반복하여 제공받음으로써 운동 학습이 되어서 점점 더 능숙한 척추의 조절로 과녁을 잘 맞추게 되면 서 자세조절이 향상되어 대동작기능과 몸통 조절 균형 능력이 향상 되었다.

결론적으로 실험군과 대조군 모두 대동작기능과 몸통의 동적 균 형 조절 능력이 유의하게 증가하였고, 대동작기능은 실험군이 대조 군보다 더 유의하게 증가하였다. 또한 실험군에서 체중을 이동하여 움직이는 동적 몸통 균형 능력이 좌우, 전후 모든 방향에서 유의하게 증가하였다. 따라서 학령기 뇌성마비 아동의 대동작기능과 몸통의 균형 능력의 향상을 위하여 시각되먹임을 이용한 척추 안정화 운동 을 신경발달학적 치료와 함께 하는 프로그램을 제안한다. 이를 통하 여 아동이 학교생활뿐 아니라 일상생활에서도 필요한 기능을 능숙
하게 하는 데 도움이 될 것이라고 생각된다.

본 연구의 제한점은 연구대상자의 적은 숫자로 인하여 일반화하기 가 어려웠고, 대상자가 연구기간 동안 다른 기관에서도 관련된 치료 를 받는 것을 통제하지 못하였다는 것이다. 또한 대상자를 실험군과 대조군으로 나눌 때 장애 분류 단계 및 장애 유형 등을 고려한 통계적 인 짝짓기를 하지 못하였고, 몸통의 균형 능력을 평가할 때 동적 균형 평가에만 치우쳐져 있어서 정적 균형 평가 항목이 없었다는 것이다. 향후 연구에서는 대상자의 특성에 따른 통계적 짝짓기를 활용하여 대상자를 실험군과 대조군으로 나누고, 몸통의 균형 능력 평가 시 정 적 균형과 동적 균형 평가 항목을 균등하게 하는 것이 필요하겠다.

\section{REFERENCES}

1. Rosenbaum P, Paneth N, Leviton A et al. A report: the definition and classification of cerebral palsy April 2006. Dev Med Child Neurol Suppl. 2007;109:8-14.

2. Bly L. Abnormal motor development. In: Slaton DS, eds, Proceednfants and Children. Philadelphia, JB Lippincott, 1983ings: Development of movement infacy, University of North Carolina at Chapel hill Division of Physical Therapy, 1980:124-35.

3. Pearson PH, Williams CE. Physical therapy services in the developmental disabilities. Illinois. Charles C Thomas Publisher, 1972:134-92.

4. Moon JK. The Effects of utilizing visual feedback on neck movement on trunk muscles activation, balance and gross motor function in the children with spastic diplegia. Yongin University. Dissertation of Doctorate Degree. 2012.

5. Bobath K. A neurophysiological basis for the treatment of cerebral palsy. 2th ed. London, Cambridge University Press, 1991.

6. Yoon JY. The effects of trunk strengthening exercise using therapeutic ball on the gross functional movements for the cerebral palsy children with spastic type. Dankook University. Dissertation of Master's Degree. 2003.

7. Saavedra S, Woollacot M, Van Donkelaar P. Head stability during quiet sitting in children with cerebral palsy: effect of vision and trunk support. Exp Brain Res. 2010;201(1):13-23.

8. Patla AE. Understanding the roles of vision in the control of human locomotion. Gait Posture. 1997;5(1):54-69.

9. Keshner EA, Woollacott MH, Debu B. Neck, trunk and limb muscle responses during postural perturbations in humans. Exp Brain Res. 1988;71(3):455-66.

10. Maffey-Ward L, Jull G, Wellington L. Toward a clinical test of lumbar spine kinesthesia. J Orthop Sports Phys Ther. 1996;24(6):354-8.

11. Hamman RG, Mekjavic I, Mallinson AI et al. Training effects during repeated therapy sessions of balance training using visual feedback. Arch Phys Med Rehabil. 1992;73(8):738-44.

12. Kim YH, Park KS, Cheon MH et al. The effect of symmetrical standing posture in cerebral palsied children after visual and auditory feedback training. Phys Ther Korea. 1994;1(1):17-24.

13. Yoon SC. The effects of visual feedback training and trunk stabilization exercise on balance ability and spasticity for stroke patients. Namseoul 
University. Dissertation of Master's Degree. 2015.

14. Kim JH. Effects of functional trunk strengthening program for children with spastic cerebral palsy. Daegu University. Dissertation of Master's Degree. 2012.

15. Seo HJ, Lee MJ, Oh TY. The effects of neck strengthening exercise on postural control in sitting position during reaching in children with spastic diplegia. J Korean Soc Neur Ther. 2012;16(16):17-24.

16. Shim HB. The effect of lower trunk stabilization exercise on muscle activity, balance and gait in patients with hemiplegia. Gachon University. Dissertation of Master's Degree. 2012.

17. Weis R. Gross motor function measure (GMFM-66 and GMFM-88) User's Manual: Dianne J. Russell, Peter L. Rosenbaum, Mary Lane, Lisa M Avery (Eds.); Cambridge University Press on behalf of Mac Keith Press, Cambridge, UK, 2002, European Journal of Paediatric Neurology. 2004;2(8):111-2.

18. Shin JW. The effect of neck and trunk stabilization exercise on motor skills and balance and visual perception of children with cerebral palsy. Daegu University Dissertation of Doctorate Degree. 2016.

19. Ryu HJ. Effects of core exercise and neck stabilizing exercise on proprioception and balance in children with cerebral palsy due to premature birth. Daegu University. Dissertation of Doctorate Degree. 2015.

20. Tecklin JS. Pediatric physical therapy. 4th ed. Philadelphia, LWW, 2008:17-61.

21. Lee EJ, Kim JS. The changes of gross motor function and balance ability in children with spastic diplegic cerebral palsy by trunk muscle strengthening exercise: Single group repeated measure study. J Korean Soc Phys
Med. 2011;6(2):189-97.

22. Jack D, Boian R, Merians AS et al. Virtual reality-enhanced stroke rehabilitation. IEEE Trans Neural Syst Rehabil Eng. 2001;9(3):308-18.

23. Lee HK, Scudds RJ. Comparison of balance in older people with and without visual impairment. Age and Ageing. 2003;32(6):643-9.

24. Lim AJ. The effect of eye movement program on postural control and visual perceptional ability of children with spastic cerebral palsy. Inje University, Dissertation of Master's Degree. 2011.

25. Bear MF, Connors BW, Paradiso MA. Neuroscience (Vol. 2). 3th ed. Philadelphia, LWW, 2007.

26. Han DW, Kong NH. The effects of the postural movement normalization and eye movement program on the oculomotor ability of children with cerebral palsy. Phys Ther Korea. 2007;14(3):32-40.

27. Jo YJ. The effects of head control training using virtual reality programs on standing balance in children with spastic hemiplegia. Yongin University, Unpublished Dissertation of Master's Degree. 2011.

28. Lee JY. The effects of eye movement exercises on balance ability and gross motor function for the children with hemiplegic cerebral palsy. Dankook University, Dissertation of Master's Degree. 2012.

29. Laufer Y. The effect of walking aids on balance and weight-bearing patterns of patients with hemiparesis in various stance positions. Phys Ther. 2003;83(2):112.

30. Cheng PT, Wang CM, Chung CY et al. Effects of visual feedback rhythmic weight-shift training on hemiplegic stroke patients. Clin rehabil. 2004;18(7):747-53. 